\title{
Valores da Amplitude de Distribuição do Tamanho dos Eritrócitos (RDW) em eqüinos Puro Sangue Inglês (PSI) submetidos a exercícios de diferentes intensidades
}

Mara Regina Stipp BALARIN ${ }^{1}$ Raimundo Souza LOPES ${ }^{2}$ Aguemi KOHAYAGAWA ${ }^{3}$ Cecilia Braga LAPOSY2 Joandes Henrique FONTEQUE ${ }^{3}$

Correspondência para: MARA REGINA STIPP BALARIN Departamento de Medicina Veterinária Preventiva

Universidade Estadual de Londrina Caixa Postal 6001 86051-990 - Londrina - PR balarima@sercomtel.com.br

Recebido para publicação: 04/11/2004 Aprovado para publicação: 01/06/2005

\author{
1 - Departamento de Medicina Veterinária Preventiva da Universidade \\ Estadual de Londrina, Londrina - PR \\ 2 - Departamento de Clínica Veterinária da Faculdade de Medicina \\ Veterinária e Zootecnia da Universidade Estadual Paulista, Botucatu - SP \\ 3 - Universidade do Oeste Paulista, Presidente Prudente - SP
}

\section{Resumo}

O presente estudo foi delineado para avaliar as alterações nos valores da amplitude de distribuição do tamanho dos eritrócitos (RDW) e do volume globular médio (VGM) em eqüinos PSI submetidos a exercícios de diferentes intensidades. Foram colhidas amostras de sangue de 60 eqüinos, PSI, sendo 30 machos e 30 fêmeas, distribuídos nos seguintes grupos: eqüinos de 24 a 36 meses de idade não submetidos a treinamento e após um período de 12 meses de treinamento; eqüinos de 36 a 48 meses de idade em fase de treinamento, antes e após o trote e antes e após o galope. As amostras foram processadas no contador automático de células Cell-Dyn 3500R (Abbott Diagnostic). Os valores médios obtidos para o RDW aumentaram significativamente após o trote e galope, demonstrando ocorrer alteração no grau de anisocitose porém os valores do VGM não apresentaram alterações nesses mesmos momentos.

\section{Introdução}

O índice mais comumente usado para avaliar o grau de anisocitose é o volume globular médio (VGM) que é tradicionalmente calculado pelo volume globular e pela contagem eritrocitária. No entanto, muitas alterações no volume dos eritrócitos não são detectadas analisando somente o VGM. Um grande percentual de células com volume alterado é necessário para produzir um VGM anormal e a avaliação morfológica das hemácias para determinar a presença de anisocitose é um método limitado devido a sua subjetividade, segundo Roberts e El Badawi ${ }^{1}$.

Tem-se buscado outras técnicas para avaliar a resposta eritrocitária em eqüinos, como a avaliação da medula óssea e de componentes dos eritrócitos que indicariam a imaturidade do eritrócito, porém, são métodos que não se aplicam na rotina clinica do eqüino atleta ${ }^{2}$.

Os contadores eletrônicos hematológicos fornecem uma informação adicional sobre o volume celular no hemograma de rotina. Tais equipamentos calculam a distribuição do diâmetro dos eritrócitos, designada RDW (Red Blood Cell Distribution Width) cujo valor reflete, de forma mais objetiva, o grau de heterogeneidade entre as hemácias por meio de uma análise quantitativa ${ }^{3}$. O RDW representa o coeficiente de variação da distribuição do volume das hemácias e pode ser considerado um índice de heterogeneidade, equivalente à anisocitose observado no esfregaço sangüíneo ${ }^{4}$.

$\mathrm{Na}$ medicina humana este índice tem sido bastante utilizado para a avaliação dos diferentes tipos de anemia ${ }^{1,5}$. O RDW é o índice mais sensível para determinar o grau de anisocitose, segundo Monzon'.

Estudando pacientes com diferentes 
1 BD-Vacultainer Sistem. 2 Cell-Dyn 3500R. Abbott Diagnostic. tipos de anemias, Roberts e El Badawi ${ }^{1}$ observaram que os valores de RDW foram proporcionais a contagem de reticulócitos, com valores mais altos em pacientes com contagem elevada de reticulócitos.

Em eqüinos os eritrócitos imaturos não são liberados para a circulação durante a resposta a uma diminuição do volume globular, portanto a observação de policromasia e anisocitose são raras e o aumento do volume globular médio (VGM) é uma alteração inconsistente nas anemias dos eqüinos, segundo Feldman et $\mathrm{al}^{7}$.

Os valores de RDW em eqüinos têmse tornado importantes para identificar o aumento da eritropoiese e avaliar a anemia. Os valores médios obtidos para eqüinos clinicamente sadios foram de 18,5\% e há necessidade de se estabelecer valores para cada laboratório e para cada espécie animal, segundo Weiser ${ }^{3}$ e Easley².

Devido a utilização cada vez mais freqüente dos contadores eletrônicos na Medicina Veterinária e a ausência de valores de referência para o índice RDW, este trabalho teve como objetivo determinar os valores de RDW em eqüinos Puro Sangue Inglês (PSI) na faixa etária de 24 a 36 meses de idade e as alterações provocadas por exercícios de diferentes intensidades, relacionando-as com os valores do VGM, que é o índice mais utilizado até o momento para avaliação do volume globular.

\section{Materiais e Métodos}

Com o objetivo de verificar a influência de um período de 12 meses de treinamento e dos exercícios de diferentes intensidades em eqüinos da raça Puro Sangue Inglês (PSI), sobre os valores da distribuição do diâmetro dos eritrócitos (RDW) e do volume globular médio (VGM) foram constituídos quatro grupos experimentais.

Grupo1: composto por 30 animais, 15 machos e 15 fêmeas, de 24 meses de idade pertencentes ao plantel do Haras Vendaval, não submetidos ao treinamento.
Foram realizadas três colheitas com os eqüinos em repouso com intervalo de 30 dias entre cada colheita.

Grupo 2: constituído por 30 eqüinos, 15 machos e 15 fêmeas, de 36 a 48 meses de idade, do Centro de Treinamento do Jockey Clube de São Paulo, submetidos a treinamentos diários. Após um período médio de 12 meses de treinamento foram realizadas três colheitas, com intervalo de 30 dias com os animais em repouso, sempre no mesmo horário, entre 5:00 e 6:00 horas.

Grupo 3: constituído de 30 animais, 15 machos e 15 fêmeas, de 36 a 48 meses de idade, do Centro de Treinamento do Jockey Clube de São Paulo, em treinamento diário por um período médio de 12 meses. Foram realizadas três colheitas com intervalo de 30 dias entre cada colheita, antes e após o exercício de intensidade moderada (trote), sendo que a colheita após o exercício era efetuada no máximo cinco minutos do mesmo.

Grupo 4: composto de 20 animais, 10 machos e 10 fêmeas, pertencentes ao grupo 2. Foi realizada uma colheita antes e uma outra imediatamente após o exercício de intensidade máxima (galope).

As amostras de sangue foram colhidas por punção da veia jugular em frascos à vácuo ${ }^{1}$ de $5 \mathrm{~mL}$ com anti-coagulante EDTA (ácido etileno-diaminotetracético-potássico) a 10\% para obtenção do volume globular médio (VGM) e da amplitude de distribuição do tamanho do eritrócito (RDW) por meio de um auto analisador hematológico ${ }^{2}$.

O RDW é obtido pelo grau de difusão da luz através das partículas entre 360 e 36fl. A difusão da luz é afetada pela forma e tamanho dos eritrócitos. Por esta razão, todas as células são uniformizadas de forma esférica, fazendo com que somente um fator afete a difusão da luz, que é o tamanho das células.

Para a análise estatística dos dados, foi realizado o teste $t$ de Student $(p<0,05)$ para as variáveis RDW e VGM, a fim de comparar machos e fêmeas. 
Tabela 1 - Valores médios e desvios padrão $(x \pm s$ ) da Amplitude de Distribuição do Tamanho dos Eritrócitos (RDW) e do Volume Globular Médio (VGM) no sangue de eqüinos PSI, machos $(n=15)$ e fêmeas $(n=15)$, entre 24 e 36 meses de idade, antes de iniciarem o treinamento e após um período médio de 12 meses de treinamento diário

\begin{tabular}{llcccc}
\hline & & \multicolumn{2}{c}{ Machos } & \multicolumn{2}{c}{ Fêmeas } \\
Exercício & Variável & Antes & Após & Antes & Após \\
\hline \multirow{2}{*}{ Treinamento } & \multirow{2}{*}{ RDW (\%) } & $27,25^{\mathrm{a}} \pm$ & $26,69^{\mathrm{b}} \pm$ & $27,36^{\mathrm{a}} \pm$ & $26,31^{\mathrm{b}} \pm 1,28$ \\
\multirow{2}{*}{ Treinamento } & $0,91^{\mathrm{N}} \pm$ & 1,31 & 1,27 & \\
& \multirow{2}{*}{$\mathrm{VGM}(\mathrm{fL})$} & $40,07^{\mathrm{b}} \pm$ & $45,09^{\mathrm{a}} \pm$ & $39,67^{\mathrm{b}} \pm 1,55$ & $45,73^{\mathrm{a}} \pm 2,98$ \\
\hline
\end{tabular}

\section{Resultados e Discussão}

$\mathrm{Na}$ tabela 1 estão apresentados os valores médios e desvios padrão da Distribuição do Diâmetro dos eritrócitos (RDW) e do Volume Globular Médio (VGM) em amostras de sangue colhidas de eqüinos PSI em repouso antes e após um período de 12 meses de treinamento.

Os valores do RDW apresentados pelos eqüinos machos e fêmeas antes de iniciarem o treinamento foram superiores aos obtidos por Weiser ${ }^{3}$, Easley ${ }^{2}$ e Radin, Eubank e Weiser ${ }^{9}$ e semelhantes aos de Balarin et al. ${ }^{8}$ quando analisaram os valores do RDW em 90 eqüinos PSI de 12 a 24 meses de idade, sem treinamento.

Radin, Eubank e Weiser', induzindo anemias em eqüinos observaram aumento significativo nos valores de RDW nos grupos com severa hemorragia e hemólise, obtendo valores máximos de $24,3 \%$ e $26,4 \%$, respectivamente $\mathrm{Os}$ valores obtidos neste estudo para eqüinos foram muito superiores aos da literatura consultada; sendo semelhantes aos obtidos por Radin, Eubank e Weiser ${ }^{9}$ em eqüinos com severa hemorragia e hemólise, justificando a necessidade de se estabelecer valores para cada laboratório e para cada espécie animal, referida por Weiser $^{3}$ e Easley ${ }^{2}$.

Os valores obtidos por Balarin et $\mathrm{al}^{8}$ em eqüinos PSI, machos e fêmeas, clinicamente sadios na faixa etária de 12 a 24 meses foram de 26,90 $\pm 1,41(\%)$ para os machos e de $26,89 \pm 1,75(\%)$ para as fêmeas.

Após 12 meses de treinamento os eqüinos deste estudo apresentaram diminuição significativa dos valores do RDW, porém ainda superiores aos da literatura consultada.

Na Medicina Veterinária o RDW vem sendo utilizado há mais de 15 anos para avaliar a resposta eritrocitária em eqüinos e em outras espécies. Porém, os estudos com eqüino atleta ainda são muito escassos. Weiser $^{3}$ e Easley ${ }^{2}$ já haviam referido a importância deste índice para identificar o aumento da eritropoiese e avaliar a anemia em eqüinos.

Como o índice de volume celular mais usado é o volume globular médio (VGM) e como sabemos que desordens no volume dos eritrócitos não são detectadas analisando somente o VGM, este índice, também, foi calculado para verificar a ocorrência de alterações após o treinamento, o trote e o galope.

Após o treinamento houve aumento significativo do VGM para ambos os sexos, que não foi acompanhado pelo aumento do RDW, havendo necessidade de maiores estudos em eqüinos durante a fase de treinamento.

$\mathrm{Na}$ tabela 2 estão apresentados os valores médios e desvios padrão da Distribuição do Diâmetro dos Eritrócitos (RDW) e do Volume Globular Médio (VGM) em amostras de sangue colhidas de eqüinos PSI em repouso e após serem submetidos a exercícios de intensidade moderada (trote) e de intensidade máxima (galope).

Para o RDW houve um aumento significante dos valores após o trote e o galope, para machos e fêmeas (Tabela 2) 
Tabela 2 - Valores médios e desvios padrão $(\mathrm{x} \pm \mathrm{s}$ ) da Amplitude de Distribuição do Tamanho dos Eritrócitos (RDW) e do Volume Globular Médio (VGM) no sangue de eqüinos PSI, machos $(n=15)$ e fêmeas $(n=15)$, entre 24 e 36 meses de idade, em repouso e após o trote e após o galope

\begin{tabular}{llcccc}
\hline & & \multicolumn{2}{c}{ Machos } & \multicolumn{2}{c}{ Fêmeas } \\
Exercício & Variável & Antes & Após & Antes & Após \\
\hline Trote & RDW (\%) & $26,69^{\mathrm{b}} \pm 1,11$ & $29,10^{\mathrm{a}} \pm 1,34$ & $26,61^{\mathrm{b}} \pm 1,28$ & $31,86^{\mathrm{a}} \pm 1,34$ \\
Trote & VGM (fL) & $45,09^{\mathrm{a}} \pm 2,99$ & $44,71^{\mathrm{a}} \pm 2,46$ & $44,42^{\mathrm{a}} \pm 2,98$ & $44,76^{\mathrm{a}} \pm 2,85$ \\
Galope & RDW (\%) & $25,95^{\mathrm{b}} \pm 1,52$ & $29,66^{\mathrm{a}} \pm 1,35$ & $26,61^{\mathrm{b}} \pm 1,44$ & $31,86^{\mathrm{a}} \pm 2,82$ \\
Galope & VGM (fL) & $45,16^{\mathrm{a}} \pm 3,33$ & $45,22^{\mathrm{a}} \pm 3,37$ & $44,42^{\mathrm{a}} \pm 3,08$ & $44,76^{\mathrm{a}} \pm 3,07$ \\
\hline
\end{tabular}

revelando ter ocorrido uma alteração no tamanho das hemácias. MaClay et al. ${ }^{10}$ e Smith et $\mathrm{al}^{11}$ observaram aumento nos valores do RDW em eqüinos após exercícios.

Em estudo com eqüinos submetidos a exercícios, Smith et al..$^{11}$ observaram aumento no tamanho dos eritrócitos que atribuíram a liberação de células pelo baço.

MaClay et al. ${ }^{10}$ determinaram os valores de RDW em eqüinos PSI durante uma competição. Os valores obtidos foram de $21,20 \pm 0,20(\%)$ e de $22,10 \pm 0,29(\%)$ para antes e após a corrida, respectivamente.

Os resultados deste estudo em eqüinos submetidos a exercícios sugerem aumento do tamanho dos eritrócitos após exercícios de alta intensidade, atribuído a eritrócitos de maior tamanho liberado pelo baço, concordando com Smith et al. ${ }^{11}$.

Os valores médios obtidos para o VGM não mostraram diferenças significativas após o trote e o galope (Tabela 2) enquanto os valores do RDW apresentaram aumento significativo tanto após o trote como após o galope, demonstrando a maior sensibilidade desse índice para avaliação da heterogeneidade do tamanho das hemácias, já proposto por Weiser e Monzon 6 .

A grande variação nos valores do VGM apresentada pela literatura e a maior sensibilidade do índice RDW demonstrada neste estudo justifica ampliar as pesquisas sobre a variação deste índice em eqüinos atletas e em outras espécies.

\section{Conclusões}

Os resultados deste estudo demonstraram aumentos significativos dos valores do RDW após exercícios de intensidade moderada e forte, não sendo acompanhados por aumento do VGM sugerindo a maior sensibilidade do índice RDW na avaliação da alteração do tamanho das hemácias.

\section{Agradecimentos}

Ao Centro de Treinamento do Jockey Clube de São Paulo, Campinas-SP e ao Haras Vendaval, Boituva-SP.

\section{Values of Red Blood Cell Distribution Width (RDW) in thoroughbred horse submitted to exercise of different intensity}

\begin{abstract}
s
In order to evaluate the influence of exercise of different intensities on Red Blood Cell Distribution width (RDW) and Packed Cell Volume $(\mathrm{VG})$ in Thoroughbred horses, blood was collected from 60 animals, 30 males and 30 females, subdivided in groups of horses with 24 to 36 months of age and not in training, and after 12 months of training, and horses with 36 to 48 months of age in training. Blood samples where collected before and after trot and gallop. Samples where analyzed with a automatic cell counter (Cell-Dyn 3500R, Abbott Diagnostic).
\end{abstract}

Key words: Red Blood Cell Distribution Width (RDW).

Horses.

Thoroughbred. Cell- Dyn 3500R. 
Red Blood Cell Distribution width (RDW) values increased significantly after trot and gallop demonstrating a variation in the size of red blood cells, while Packed Medium Cell Volume (VGM) values did not show variations before or after exercise.

\section{Referências}

1 ROBERTS, G. T.; EL BADAWI, S. B. Red cell distribution width index in some hematologic diseases. American Journal Clinical Pathology. v. 83, n. 2, p. 226-236, 1995.

2 EASLEY, J. R. Erythrogram and red cell distribution width of equidae with experimentally induced anemia. American Journal Veterinary Research, v. 46, n. 11, p. 2378-2384, 1985.

3 WEISER, G.; KOHN, C.; VACHON, A. Erythrocyte volume distribution analysis and hematologic changes in two horses with immune-mediated hemolytic anemia. Veterinary Pathology, v. 20, p. 424-433, 1983.

4 KARNAD, A.; POSKITT, T. R. The automated complete blood cell count - use of the red blood coll volume distribution width and mean platelet volume in evaluating anemia and thrombocytopenia. Archives of Internal Medicine. ,v. 145, p. 1270-1272, 1985.

5 ROMERO-ARTAZA, J. Red cell distribution width (RDW): its use in the characterization of microcytic and hypocromic anemias. Medicina (Buenos Aires), v. 59, n. 1, p. 17-22, 1999.

6 MONZON, C. M.; BEAVER, B. D.; DILLON, T. D. Evaluation of erythrocyte disorders with mean corpuscular volume (MCV) and red cell distribution width (RDW). Clinical Pediatrics, v. 26, n. 12, p. 632638, 1986.

7 FELDMAN, B. F.; ZINKL, J. G.; JAIN, N. C. Schalm's veterinary hematology. 5 . ed. Philadelphia: Williams \& Wilkins, 2000. 1344 p.

8 BALARIN, M. R. S.;et al. Valores da amplitude de distribuição do tamanho dos eritrócitos (RDW - Red Cell Distribution Width) em eqüinos da raça Puro Sangue Inglês (PSI) de ambos os sexos de 12 a 24 meses de idade. Semina: Ciências Agrárias, Londrina, v. 22, n. 2, p. 135-137, 2001.

9 RADIN, M. J.; EUBANK, M. C.; WEISER, M. G. Electronic measurement of erythrocyte volume and volume heterogeneity in horses during erythrocyte regeneration associate with experimental anemias. Veterinary Pathology, v. 23, n. 6, p. 656-660, 1986.

10 MaCLAY, C. B.; et al. Evaluation of hemorheologic variables as implication for exercise-induced pulmonary hemorrhage in racing Thoroughbred. American Journal Veterinary Research, v. 53, n. 8, p. 1380-1385, 1992.

11 SMITH, J. E., ERICKSON, H. H.; DEBOWES, R. M. Changes in circulating equine erythrocytes induced by brief, high-speed exercise. Equine Veterinary Journal. v. 21, n. 6, p. $444-446,1989$

12 WEISER, M. G. Erythrocyte volume distribution analysis in health dogs, horses, and dairy cattle. American Journal Veterinary Research, v. 43, p. 163-166, 1982. 